\title{
Occurrence of pathogenic fungi on commercially available medicinal plants and packaged seeds
}

\author{
LIDIA IRZYKOWSKA ${ }^{* 1}$, KATARZYNA WIELGUSZ $^{2} \odot$
}

\author{
${ }^{1}$ Department of Phytopathology, Seed Science and Technology \\ Poznań University of Life Sciences \\ Dąbrowskiego 159 \\ 60-594 Poznań, Poland \\ ${ }^{2}$ Department of Agriculture of Useful Plants \\ Institute of Natural Fibres and Medicinal Plants - National Research Institute \\ Wojska Polskiego 71b \\ 60-630 Poznań, Poland \\ *corresponding author: phone: 486184879 27; e-mail: lidia.irzykowska@up.poznan.pl
}

\section{Summary}

Introduction: Pathogenic fungi decrease the quality of commercially available medicinal plants and packaged seeds. Some of fungal pathogens can produce mycotoxins harmful to human health.

Objective: To evaluate the health status of commercially available medicinal plants and check if packaged seeds of these plants are free from pathogenic fungi.

Methods: An experiment was conducted on potted plants of lemon balm, peppermint and sweet basil, commercially available and intended for direct use by consumers. For microbiological analyses, 100 stems and leaves of each species were randomly taken. Furthermore, the health of 100 seeds of each species was examined using agar plate method.

Results: Ten species and genera of pathogenic fungi were isolated from shoots, leaves and seeds of investigated plants. Some of them are toxin-forming species. Lemon balm was the most infected species.

Conclusion: Bearing in mind the health of consumers, more attention should be paid to the microbiological purity of commercially available medicinal plants and packaged seeds.

Key words: Lamiaceae, mycotoxins, Melissa officinalis, Mentha piperita, Ocimum basilicum, pathogenic fungi

Słowa kluczowe: Lamiaceae, mykotoksyny, Melissa officinalis, Mentha piperita, Ocimum basilicum, grzyby chorobotwórcze 


\section{INTRODUCTION}

Plants have been utilized as medicines throughout human history. Nowadays, people have been searching for natural products supplementing and improving their diet. Medicinal plants (MPs) are used as a source of biologically active compounds with therapeutic properties. The most popular herbs are lemon balm (Melissa oficinalis L.), mint (Mentha piperita L.), and sweet basil (Ocimum basilicum L.), belonging to Lamiaceae family. They are extensively applied to cure neurological diseases [1] and digestive system problems [2].

M. officinalis is a herbal remedy used to treat anxiety and insomnia, attention deficit-hyperactivity disorder (ADHD), elevated blood pressure and irregular heartbeat due to nervousness [3]. Fresh herbs contain phenolic compounds, l-ascorbic acid, carotenoids, flavonoids and terpenoids. Due to the high content of flavonoids in leaves this herb has antioxidant properties. Lemon balm due to its health promoting properties, apart from medical use, is also increasingly used as an ingredient in supplements and functional foods [4]

$M$. piperita is one of the most widely consumed single ingredient of herbal teas used in traditional medicines. The phenolic constituents of the leaves include rosmarinic acid and several flavonoids. The main volatile components of the essential oil are menthol and menthone [5]. Peppermint has a relaxation effect on gastrointestinal tissue, analgesic and anaesthetic effects in the central and peripheral nervous systems, immunomodulating actions and chemopreventive potential. Studies in humans concerning the respiratory tract and analgesic effects of peppermint oil and its constituents have been reported [6].

O. basilicum is a popular herb due to its pleasant aroma and taste but it also has a beneficial effect in gastric diseases. Sweet basil contains functional ingredients such as phenolic acids (chlorogenic, $p$-hydroxybenzoic, caffeic, ferulic, vanillic, cinnamic and rosmarinic) and flavonoids (quercetin, naringenin, rutin) [7]. This herb is commonly used for stomach problems such as spasms, loss of appetite and intestinal gas. Recent scientific research has investigated the health benefits associated with essential oils of basil. Studies reveal the antioxidant, anti-microbial, antiviral, and anti-cancer properties of the oils [8].

People often buy commercially available readymade herb seedlings or grow them as amateurs on balconies or in home gardens. Therefore, the quality of the seeds and seedlings is very important. We can only talk about the health benefits of herbs in the diet if they are free of microbiological contamination, especially of pathogenic fungi. Fungal pathogens, while overgrowing plant tissues, damage secretory tissue, which cause a decrease in the amount of essential oil contained in infected plants and changes the composition of volatile fractions in plants [9]. Some microscopic fungi mainly these belonging to genera Fusarium, Aspergillus, Penicillium and Alternaria can strongly decrease the quality of MPs by biosynthesizing mycotoxins [1]. Mycotoxins are highly toxic secondary metabolic products of fungi, harmful to human health.

Today, potted lemon balm, mint and sweet basil plants as well as seeds for their production are readily available in various hypermarkets. However, the health of these plants is sometimes questionable, they often show symptoms of disease or die off and consumers cannot assess the reasons for this phenomenon.

The aim of this study was to evaluate the species composition of fungi infecting commercially available peppermint, lemon balm and sweet basil, as well as to check if packaged seeds of these plants are free from pathogenic fungi.

\section{MATERIAL AND METHODS}

An experiment was conducted on potted medicinal plant species commercially available in hypermarkets and intended for direct use by consumers. Three medicinal species were investigated as follows: sweet basil (Ocimum basilicum L.), peppermint (Mentha $x$ piperita L.) and lemon balm (Melissa officinalis L.). For microbiological analyses, 20 pots (of 10 from 2 different batches) with plants of each species were used. First, plants were visually assed for the presence of the disease symptoms such as: leaf wilting, discolorations and etiological sings on aboveground part of plants. Then, 5 stems and 5 leaves were randomly taken from each pot, one hundred stems and leaves of each species in total.

For the test of the seed material of the abovementioned species, packaged seeds from one German and one Polish seed company, commonly used in amateur crop breeding, were used.

Plant material used for mycological analysis was disinfected by soaking in $1 \%$ solution of sodium hypochlorite for $1 \mathrm{~min}$. and finally rinsed with distilled water. The disinfected leaves were cut into $2-3 \mathrm{~mm}$ long pieces and the stems into $0.5 \mathrm{~mm}$ long fragments. Sections of tissues were placed into Petri dishes containing potato dextrose agar (PDA) medium amended with streptomycin at $100 \mu \mathrm{g} \mathrm{ml}^{-1}$ and incubated within 5 days at $25^{\circ} \mathrm{C}$. The mycelium growing 
out from the plant fragments was transferred to fresh PDA medium in order to obtain pure cultures. Synthetic nutrient-poor agar (SNA) medium was used for Fusarium species identification.

To assess the health of seeds, agar plate method was applied. One hundred seeds (of 50 from two different companies) of each species was surface disinfected with $1 \%$ sodium hypochlorite for $5 \mathrm{~min}$., rinsed with distilled water and placed into Petri dishes containing PDA medium. The plated seeds were incubated for 7 days at $25^{\circ} \mathrm{C}$ under 12 alternating cycles of light and darkness. The Petri dishes were monitored every day to check the growth of fungal colonies from seeds and to obtain pure cultures.

Fungi growing out from stems, leaves and seeds were identified based on colony characters and morphology of sporulating structures according to available monographs $[10,11]$.
Ethical approval: The conducted research is not related to either human or animal use.

\section{RESULTS AND DISCUSSION}

The analysis of commercially available potted medicinal plants showed that some of these plants should be withdrawn from the market. The health of packaged seeds intended for sowing by amateurs was also questionable.

Visual evaluation of the stems and leaves of basil, mint and lemon balm plants showed the presence of brown discolorations, mycelium and spores on some plants. Isolates of fungi representing 10 species and genera were obtained from examined parts of medicinal plants. The greatest number of isolates came from leaves, while slightly fewer from stems (tab. 1, 2,3).

Table 1.

Fungal species isolated from lemon balm and percentage of infected plant parts

\begin{tabular}{lccc}
\hline \multirow{2}{*}{ Fungal species } & \multicolumn{4}{c}{ Percentage of plant parts infected by pathogenic fungi [\%] } \\
\cline { 2 - 5 } & stem & leaves & seeds \\
\hline Alternaria alternata & 16 & 27 & 18 \\
\hline Botrytis cinerea & 1 & 8 & 13 \\
\hline Fusarium culmorum & 4 & - & - \\
\hline Fusarium equiseti & 9 & - & - \\
\hline Septoria melissae & - & 4 & 3 \\
\hline Ulocladium atrum & 5 & 3 & \\
\hline
\end{tabular}

Table 2.

Fungal species isolated from peppermint and percentage of infected plant parts

\begin{tabular}{lccc}
\hline \multirow{2}{*}{ Fungal species } & \multicolumn{3}{c}{ Percentage of plant parts infected by pathogenic fungi [\%] } \\
\cline { 2 - 5 } & stem & leaves & seeds \\
\hline Alternaria alternata & 9 & 16 & 8 \\
\hline Botrytis cinerea & - & 3 & 6 \\
\hline Fusarium culmorum & 4 & - & - \\
\hline Fusarium oxysporum & 6 & - & - \\
\hline Puccinia menthae & - & 2 & - \\
\hline
\end{tabular}

Table 3.

Fungal species and genera isolated from sweet basil and percentage of infected plant parts

\begin{tabular}{lccc}
\hline \multirow{2}{*}{ Fungal species } & \multicolumn{3}{c}{ Percentage of plant parts infected by pathogenic fungi [\%] } \\
\cline { 2 - 5 } & stem & leaves & seeds \\
\hline Alternaria alternata & 5 & 9 & 8 \\
\hline Botrytis cinerea & 4 & 6 & 2 \\
\hline Cladosporium sp. & 4 & 5 & - \\
\hline Fusarium oxysporum & 6 & - & - \\
\hline Penicillium sp. & - & - & 3 \\
\hline
\end{tabular}


All three studied species and their seeds were infested by polyphagous fungi: Alternaria alternata, Botrytis cinerea and also stems of different species of Fusarium genus. The scientific literature lacks data on the health of commercially available MPs and packaged seeds but in the field experiments similar results were obtained [12].

$M$. officinalis was the most infected species (tab.1). In addition to the species listed above, single isolates of S. melissae and U. atrum were obtained in this study, while in field crops $S$. melissae is often the dominant species [13].

$M$. piperita was infested by fungi to a lesser extent than lemon balm (tab. 2). Five species of pathogenic fungi were isolated from the mint plant material: A. Alternata, B. cinerea, F. culmorum, F. oxysporum and $P$. menthae. The A. alternata species was most severely observed on the stem, leaves and seeds. The leaves were most severely affected by this fungus species. The presence of $B$. cinerea has been demonstrated on seeds and on mint leaves. The mint leaves were also affected by the species Puccinia menthae, which causes mint rust. Fusarium fungi were isolated only from stems. The occurrence of these species of fungi was found on many mint plantations in various regions of Poland [14]. Therefore, it is very important to observe the principles of proper agricultural technology (e.g. proper crop rotation, fertilization) in order to eliminate this problem. It is important because the spores of fungal pathogens, as shown by the conducted research, occur on commercial raw material.

O. basilicum was the most microbiologically pure of the MPs studied. However, there are some pathogens that could cause stem and leaf damage especially in high humidity conditions when sweet basil is very sensitive ( $\operatorname{tab} 3$ ).

The species $A$. alternata is a pathogen that can infect basil stems, leaves and seeds under favorable weather conditions [15]. The tests showed the presence of this pathogen on all these parts of the plant. The $B$. cinerea species has also been isolated from all parts of the plant. The presence of fungi of the genus Cladosporium has been observed on leaves and stems. Fungi of the species F. oxysporum were present on the stems. Transmission of this species by seeds has been described in previous studies [16]. In addition, the presence of Penicillium fungi was observed on sweet basil seeds. It is a species that may have appeared as a result of inadequate storage of the seed material.

The most frequent pathogens isolated from packaged seeds were $A$. alternata and $B$. cinerea, which is reflected in the literature [10]. Some seeds were colonized by two or more pathogens simultaneously. Depending on the species of MPs, fungi were isolated from $2-18 \%$ of the analysed seeds.

Results of mycological analysis showed that stems and leaves of examined lemon balm, peppermint and sweet basil plants were colonized by a complex of pathogens, among which species capable of mycotoxin biosynthesis (Fusarium spp., Penicillium sp., A. alternata) are of particular concern. Mycotoxins are toxic compounds that are naturally produced by certain fungi. In MPs, exposure to mycotoxins can happen directly by eating infected plant parts or infusions. Most mycotoxins are chemically stable and survive food processing. It is known that more than 300 of these fungal metabolites are toxic to humans.

Some isolates of Fusarium spp. are able to produce a range of different toxins, including trichothecenes and fumonisins. Isolates of Fusarium oxysporum obtained from sweet basil can form both moniliformin $(\mathrm{MON})$ and fumonisin $\mathrm{B}_{1}$ (FB1) [17]. A. alternata can produce tenuazonic acid (inhibitor of protein synthesis) and alternariol (teratogen and mutagen) [18]. In addition, the spores of Alternaria spp. are a strong allergen, so in some cases, an apparent allergy to herbs may actually be an allergy to this fungus. Species of the Penicillium genus can biosynthesize penicillin acid, citrinin and patulin which can have a carcinogenic effect [19].

Studies have shown that in some cases people who want to naturally support the treatment of their ailments may be exposed to pathogenic fungi and their toxins. In view of steadily increasing demand of MPs quality and for the health of consumers, higher attention should be paid to the microbiological purity of commercially available medicinal plants and packaged seeds.

\section{CONCLUSIONS}

1. Commercially available potted MPs and package seeds can be infected by pathogenic fungi.

2. Some of these fungi are able to biosynthesise mycotoxins harmful to the health of consumers.

3. Herbs with visible diseases symptoms should not be used.

4. Growing MPs with package seeds on your own seems to be a bit safer than using potted herbs available in supermarkets, sometimes badly stored and diseased.

Conflict of interest: Authors declare no conflict of interest. 


\section{REFERENCES}

1. Wielgusz K, Irzykowska L. Occurrence of pathogenic and endophytic fungi and their influence on quality of medicinal plants applied in management of neurological diseases and mental disorders. Herba Pol 2017; 63(4):57-69. doi: https:// dx.doi.org/10.1515/hepo-2017-0025

2. Calvo MI, Akerreta S, Cavero RY. The pharmacological validation of medicinal plants used for digestive problems in Navarra, Spain. Europ J Integr Med 2013; 5:537-546. doi: https://dx.doi. org/10.1016/j.eujim.2013.07.002

3. Szczeponek A, Mazur S. Occurrence of fungal diseases on lemon balm (Mellissa officinalis L.) and peppermint (Mentha piperita L.) in the region of Małopolska. Commun Agric Appl Biol Sci 2006; 71(3B):1109-1118.

4. Świąder K, Startek K, Wijaya CH. The therapeutic properties of lemon balm (Melissa officinalis L.): Reviewing novel findings and medical indications. J Appl Bot Food Qual 2019; 92:327-335. doi: https://dx.doi.org/10.5073/JABFQ.2019.092.044

5. McKay DL, Blumberg JB. A review of the bioactivity and potential health benefits of peppermint tea (Mentha piperita L.). Phytother Res 2006; 20(8):619-33. doi: https://dx.doi.org/10.1002/ ptr.1936

6. Mahendran G, Rahman LU. Ethnomedicinal, phytochemical and pharmacological updates on peppermint (Mentha piperita L.) - a review. Phytother Res 2020; 34(9): 2088-2139. doi: https:// dx.doi.org/10.1002/ptr.6664

7. Teofilović B, Grujić-Letić N, Karadžić M, Kovačević S, Podunavac-Kuzmanović S, Gligorić E, Gadžurić S. Analysis of functional ingredients and composition of Ocimum basilicum. South Afr J Bot 2021; 141:227-234. doi: https://dx.doi. org/10.1016/j.sajb.2021.04.035

8. B. Božin, Mimica-Dukić N, Simin N, Anačkov G. Characterization of the volatile composition of essential oils of some Lamiaceae spices and the antimicrobial and antioxidant activities of the entire oils. J Agric Food Chem 2006; 54(5):18221828. doi: https://dx.doi.org/10.1021/jf051922u
9. Zechini A, D'Aurelio AZ, Zambonelli A, Bianchi A, Alabasini A. Micromorphological and chemical investigation into the effects of fungal diseases on Melissa officinalis L., Mentha x piperita L. and Salvia officinalis L. J Phytopathol 1995; 143:179-83. doi: https://dx.doi.org/10.1111/j.1439-0434.1995. tb00255.x

10. Mathur SB, Kongsdal O. Common laboratory seed health testing methods for detecting fungi. Danish Govt. Institute of Seed Pathology for Developing Countries, Copenhagen 2003, pp.425.

11. Leslie JF, Summerell BA. The Fusarium laboratory manual. Blackwell Publishing, Hoboken 2006, pp. 388 doi: https://dx.doi. org/10.1002/9780470278376

12. Wielgusz K, Seidler-Łożykowska K. Fungi colonizing and damaging different parts some medicinal plants. Herba Pol 2017; 63(2):18-26. doi: https://dx.doi.org/10.1515/hepo-2017-0009

13. Kovács G, Zámbori-Németh E, Nagy G. Susceptibility of lemon balm (Melissa officinalis L.) varieties to septoria leaf spot (Septoria melissae Desm.) in Hungary. Acta Sci Pol Hort Cultus 2019; 18(1):47-56. doi: https://dx.doi.org/10.24326/asphc.2019.1.5

14. Zimowska B. Fungi colonizing and damaging different parts of peppermint (Mentha piperita L.) cultivated in South-Eastern Poland. Herba Pol 2007; 53(4):97-106.

15. Garibaldi A, Gilardi G, Bertaldo C, Gullino ML. First report of a leaf spot of sweet basil (Ocinum basilicum L.) caused by Alternaria alternata in Italy. J Plant Pathology 93 (4 supplement) S4.63 -S4.89 2011. doi: https://dx.doi.org/10.4454/jpp. v93i4.2376

16. Vannaci G, Cristani C, Fronti M, Kontoudakis G, Gambogi G. Seed transmission of Fusarium oxysporum f. sp. basilici in sweet basil. J Plant Pathology 1999; 81(1):47-53

17. Irzykowska L, Bocianowski J, Waśkiewicz A, Weber Z, Golinski P, Karolewski Z et al. Genetic variation of Fusarium oxysporum isolates forming fumonisin B1 and moniliformin. J Appl Genet 2012; 53:237-247. doi: http://dx.doi.org/10.1007/ s13353-012-0087-Z 
18. Logrieco A, Moretti A, Solfrizzo M. Alternaria toxins and plant diseases: an overview of origin, occurrence and risks. World Mycotoxin J 2009; 2(2):129-140. doi: http://dx.doi.org/10.3920/ WMJ2009.1145
19. Perrone G, Susca A. Penicillium species and their associated mycotoxins. Methods Mol Biol 2017; 1542:107-119. doi: http://dx.doi.org/10.1007/9781-4939-6707-0_5 